\title{
Downdraft Co-gasification of Oil Palm Frond with Other Oil Palm Residues: Effects of Blending Ratio
}

\author{
M.N.Z. Moni ${ }^{1,}{ }^{*}$, S.A. Sulaiman ${ }^{1}$ and A.T. Baheta ${ }^{1}$ \\ ${ }^{1}$ Mechanical Engineering Department, Universiti Teknologi PETRONAS, 31750 Bandar Seri \\ Iskandar, Perak, Malaysia.
}

\begin{abstract}
As the largest amount of biomass residues produced from the palm oil industry, the oil palm frond (OPF) is a promising solid fuel resource for gasification. However, the difficulty in processing OPF into solid fuel may affect the solid fuel production rate and consequently the gasifier operation. To ensure a continuous gasifier operation unaffected by the shortage of OPF fuel, empty fruit bunch (EFB), palm mesocarp fiber (PMF) and palm kernel shell (PKS) were introduced as a pairing fuel with OPF for co-gasification. The potentials of the fuel mixes and the effects of the fuel blending ratio on syngas higher heating value, specific syngas yield, carbon conversion efficiency and cold gas efficiency were studied. The experiments concluded that all fuel mixes of all blending ratios satisfied all the syngas quality indicator requirements and that all the tested fuel mixes can be utilized for downdraft co-gasification to produce results similar to the downdraft gasification of $100 \%$ OPF.
\end{abstract}

\section{Introduction}

Malaysia is currently the world's second largest palm oil producer, accounting for $39 \%$ of world palm oil production and $44 \%$ of world palm oil export. To date, there are over 5.4 million hectares of oil palm plantation and more than 400 palm oil mills in the country, with annual production and processing capacities of more than 90 million tons of fresh fruit bunch (FFB) [1,2]. The palm oil industry generates abundant amount of biomass residues from its plantation and milling activities, where the ratio of the residues to crude palm oil (CPO) is 9:1 as reported by Abdullah and Sulaiman [3]. In 2014, the country's palm oil industry produced around 19.96 million tons of CPO [4], and the biomass residues generated were estimated to be more than 180 million tons on a wet basis.

There are several types of solid oil palm residues. Oil palm plantation produces two types of residues: oil palm trunks (OPT) and oil palm fronds (OPF). OPT are only produced during replanting season (once every 25-30 years), while OPF are produced during FFB harvesting and regular maintenance and are available throughout the year. Palm oil mill produces three types of residues on a daily basis as a result of the CPO extraction processes from the FFB: empty fruit bunches (EFB), palm mesocarp fiber (PMF) and palm kernel shell (PKS). Only

\footnotetext{
*Corresponding author: mohdhazwan@ump.edu.my
} 
$20 \%$ of FFB accounts for CPO, while the rests are residues [5]. Based on the availability of oil palm biomass in 2007 [3], the weight percentage for each residue is shown in Fig. 1. Note that OPT were excluded from the statistics due to their seasonal availability, whereas the rests of the residues are available all year long.

In current practice, OPF are left in rows and piles in between oil palm trees after pruning for soil conservation and nutrient recycling, or used as feeding material for domestic ruminant animals in a small quantity [6]. At the mill, a small portion of the mill-based residues are used as a boiler fuel for the mill consumption while the rests are returned back to the plantation as mulch. The abundance of palm oil biomass residues led to several successful attempts in converting these otherwise underutilized and worthless wastes into value added products, one of them being solid fuel for gasification.

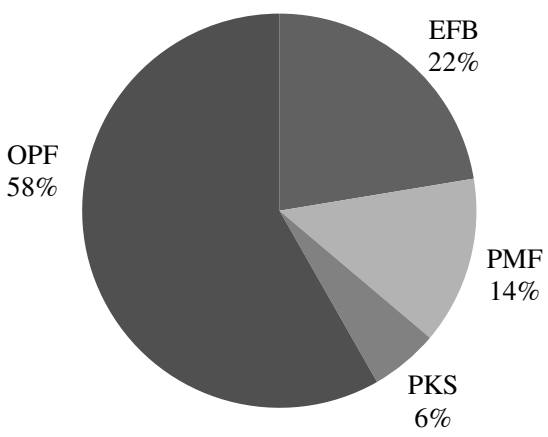

Fig. 1. The ratio of selected biomass residues from palm oil industry in Malaysia.

Gasification is a method to thermally convert solid carbonaceous material into synthesis gas or syngas, which itself is a fuel, through substoichiometric combustion technique. Majorly composed of carbon monoxide $(\mathrm{CO})$, hydrogen $\left(\mathrm{H}_{2}\right)$, carbon dioxide $\left(\mathrm{CO}_{2}\right)$ and methane $\left(\mathrm{CH}_{4}\right)$, syngas is combustible and can be utilized as fuel in combustion engines, gas turbines, furnaces and cooking stove or as a raw material for hydrogen and methanol fuel productions [7]. The versatility of syngas makes gasification an attractive method in converting biomass rather than just into heat through direct firing. In the recent years, oil palm biomass residues have been successfully tested as fuels for gasification [8-12]. OPF, being the largest amount of biomass residues generated from the palm oil industry, has been continuously tested for gasification and was concluded as a promising solid fuel resource $[13,14]$.

However, producing solid fuel from OPF is difficult and energy and time consuming particularly due to the physical aspects of OPF. Freshly-pruned OPF is large in size relative to PKS, PMF and EFB, and may contain up to $70 \%$ moisture. The leaflets that grow laterally along OPF need to be removed to avoid complications during gasification process due to the differences in density and shape, and the OPF need to be chopped down into block or chip size to fit the gasifier fuel requirement. The processing of OPF may take days for sizing and drying stages, and this may affect the fuel supply chain. For this reason, a pairing fuel is required to supplement $\mathrm{OPF}$ in ensuring uninterrupted gasification process and syngas production in the case of a fuel shortage through a method known as co-gasification. EFB, PKS and PMF were selected as pairing fuels with OPF mainly due to their constant availability in bulk amount at palm oil mills. Their post-processing shapes and sizes and their centralized collection point make EFB, PKS and PMF convenient as solid fuel materials. Also, the residues have normally been exposed to the environment for several days, causing 
their moisture contents to drop up to half of the original, making them considerably suitable as efficient solid fuels.

The objectives of this study was to examine the potentials of co-gasifying OPF-EFB, OPF-PKS and OPF-PMF fuel combinations to produce syngas of similar quality as produced by the gasification of $100 \%$ OPF solid fuel, and to investigate the effects of fuel blending ratios to syngas quality and gasification efficiency. In this study, OPF was combined with EFB, PMF or PKS to form fuel mixes of various blending ratios and tested in a downdraft gasifier to study the blending effects on the quality of the produced syngas. The syngas and gasification parameters such as the high heating value (HHV), specific syngas yield, carbon conversion efficiency (CCE) and the cold gas efficiency (CGE) were also studied. Should the quality of syngas produced by the fuel mixes reflect a similar quality to the syngas produced from $100 \% \mathrm{OPF}$, the fuel mixes can be utilized to temporarily or permanently replace a certain portion of OPF in the event of OPF fuel shortage to ensure uninterruptible gasifier operation and syngas productions.

\section{Methodology}

\subsection{Experimental setup}

An electrical-powered externally-heated downdraft gasifier unit was used as the gasification reactor. The specifications of the gasifier are shown in Table-1. The dimensions of the reaction tube and the exhaust pipeline pose a few operation limitations. Only samples with apparent dimensions of not lower than $1 \mathrm{~mm}$ and not exceeding $5 \mathrm{~mm}$ are suitable for gasification in the reactor. Samples with apparent dimensions larger than $5 \mathrm{~mm}$ will create too many voids in the fuel stack in the reactor whereas samples with smaller apparent dimensions will make the fuel stack to be too packed. The moisture content in the samples also has to be kept as close to $0 \%$ to avoid excessive liquid formation in the reactor and the pipeline during gasification. Gas compositions were continuously via a sampling line into the Emerson-Rosemount Analytical Online Gas Analyzer, where the concentrations of major syngas components $\left(\mathrm{CO}, \mathrm{CO}_{2}, \mathrm{CH}_{4}\right.$ and $\left.\mathrm{H}_{2}\right)$ were shown in volumetric percentage. The combustibility of the produced syngas was tested using a handheld lighter at the flaring point.

\subsection{Materials}

Freshly-pruned OPF and freshly-processed EFB, PKS and PMF were collected from a nearby plantation and palm oil mill. The residues were dried at $105 \pm 0.1^{\circ} \mathrm{C}$ for 24 hours. The dried residues were separately ground using a granulator into size passing a $5 \mathrm{~mm}$ screen. The ground residues were sieved using a $3 \mathrm{~mm}$ and a $1 \mathrm{~mm}$ screens to obtain samples with an apparent particle dimension range of 2-3 mm. The blending of OPF with EFB, PKS or PMF was done at 20/80, 40/60, 60/40 and 80/20 ratios by weight. Each fuel mix was placed in an airtight container and shaken to ensure homogeneity of the mixture. Prior to gasification, all fuel mixes were dried again at $105 \pm 0.1^{\circ} \mathrm{C}$ for 24 hours to ensure that their moisture content remained below $1 \%$. The ultimate and proximate analyses and calorific values of OPF, EFB, PMF and PKS are shown in Table-1. 
Table 1. Properties of OPF, EFB, PKS and PMF.

\begin{tabular}{|l|r|r|r|r|}
\hline Residues & \multicolumn{1}{|c|}{ OPF } & \multicolumn{1}{|c|}{ EFB } & \multicolumn{1}{l|}{ PKS } & \multicolumn{1}{c|}{ PMF } \\
\hline Origin & Field & Mill & Mill & Mill \\
\hline VM, \% db. & 83.19 & 84.61 & 81.03 & 81.52 \\
\hline FC, \% db. & 12.91 & 9.89 & 14.87 & 11.38 \\
\hline Ash, \% db. & 3.90 & 5.50 & 4.10 & 7.10 \\
\hline C, \% & 42.10 & 40.73 & 49.65 & 40.97 \\
\hline H, \% & 5.46 & 5.75 & 6.13 & 5.96 \\
\hline $\mathrm{N}, \%$ & 0.70 & 1.40 & 0.41 & 0.77 \\
\hline S, \% & 0.13 & 0.22 & 0.48 & 0.51 \\
\hline O, \% (by diff.) & 51.61 & 51.90 & 43.33 & 51.79 \\
\hline CV, MJ/kg & 17.25 & 18.6 & 20.4 & 18.66 \\
\hline
\end{tabular}

\subsection{Experimental method}

OPF was used as the base or primary fuel for gasification while EFB, PMF and PKS were used as the supplementary or secondary fuels. Three pairings of OPF-EFB, OPF-PMF and OPF-PKS were created, with blending ratios of 20/80, 40/60, 60/40 and 80/20. Each unmixed OPF, EFB, PMF and PKS was also individually gasified for results comparison. Gasification temperatures were tested at $700^{\circ} \mathrm{C}, 800^{\circ} \mathrm{C}$ and $900^{\circ} \mathrm{C}$. The equivalence ratio (ER) was maintained at 0.25 for all samples.

In each gasification test, $200 \pm 0.01 \mathrm{~g}$ of fully-dried fuel mix was measured using a Mettler-Toledo precision balance. The gasifier was first heated up to the desired gasification temperature before the fuel mix was inserted and the reactor was secured in order to subject the sample to fast pyrolysis as it normally occurs in actual gasifiers. The composition of syngas was continuously tested, monitored and logged using the Emerson-Rosemount Analytical Online Gas Analyzer. Flaring was initiated as soon as the produced syngas reached the flare point using a handheld lighter, and the stable, unassisted flaring duration was monitored and recorded. The gas compositions, higher heating value (HHV), specific syngas yield, carbon conversion efficiency (CCE) and cold gas efficiency (CGE) of syngas from each sample were then calculated, tabulated and analyzed. The HHV, specific syngas yield, CCE and CGE of the produced syngas must satisfy the ranges shown in Table-2. The ranges were developed based on the data obtained from several previous downdraft gasification of OPF. This was to ensure that the quality of the syngas produced from the mixed fuel is similar or close to that of syngas produced from $100 \%$ OPF.

Table 2. The syngas quality indicators and their acceptable range.

\begin{tabular}{|l|r|}
\hline Quality indicator & Range \\
\hline $\mathrm{HHV}, \mathrm{MJ} / \mathrm{Nm}^{3}$ & $4.5-5.5$ \\
\hline Specific syngas yield, $\mathrm{Nm}^{3} / \mathrm{kg}$ & $1.8-2.5$ \\
\hline CCE, $\%$ & $>75$ \\
\hline CGE, $\%$ & $>63$ \\
\hline
\end{tabular}




\section{Results and discussions}

\subsection{Gas compositions}

The change in syngas composition will directly affect the HHV, the CCE and the CGE. Normally, the $\mathrm{CO}$ and $\mathrm{H}_{2}$ components in syngas are kept at the highest possible to obtain high HHV, CCE and CGE values. The compositions of syngas produced from various blend ratios of OPF-EFB, OPF-PMF and OPF-PKS at $700^{\circ} \mathrm{C}$ gasification temperature and $0.25 \mathrm{ER}$ are shown in Fig. 3 to Fig. 4. Essentially, the production trends of syngas components were found to be agreeable with published results from other authors. The observations made on the OPF-EFB and the OPF-PMF fuel mixes revealed nearly similar syngas composition trends, while the OPF-PKS showed noticeable differences in productions with regards to changing blend ratios. The significant increment of $\mathrm{CO}$ and reduction of $\mathrm{CO}_{2}$ and $\mathrm{H}_{2}$ in OPFPKS blends were due to the contents of elemental carbon in PKS which is higher than that in OPF. Therefore, with increasing PKS composition in the fuel mixes, the higher elemental carbon content in the mix and the higher the production of $\mathrm{CO}$ will be, causing a reduction in $\mathrm{CO}_{2}$ production, since $\mathrm{CO}$ formation is more favorable at substoichiometric combustion state.

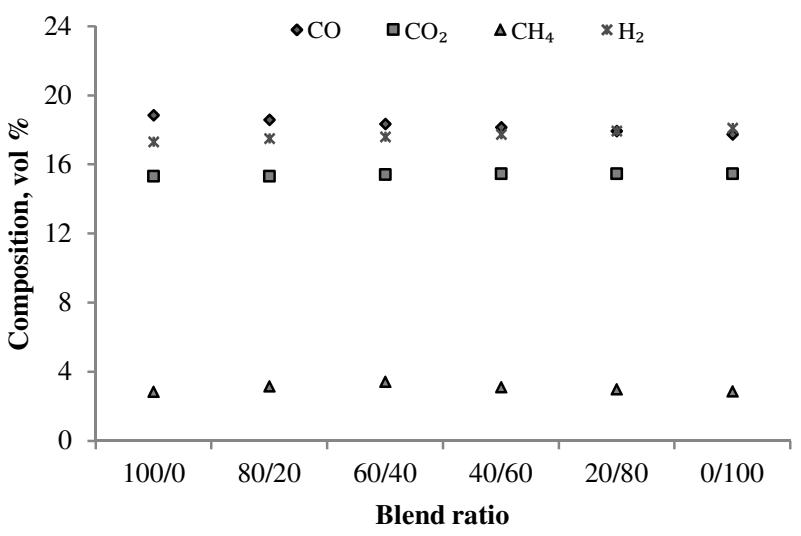

Fig. 2. Syngas components from downdraft gasification of OPF-EFB fuel mixes at $700^{\circ} \mathrm{C}$ and 0.25 ER.

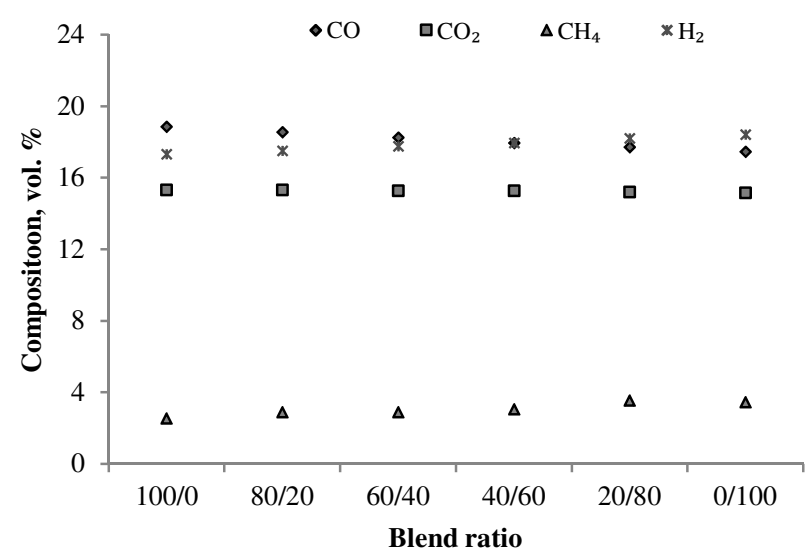

Fig. 3. Syngas components from downdraft gasification of OPF-PMF fuel mixes at $700^{\circ} \mathrm{C}$ and 0.25 ER. 


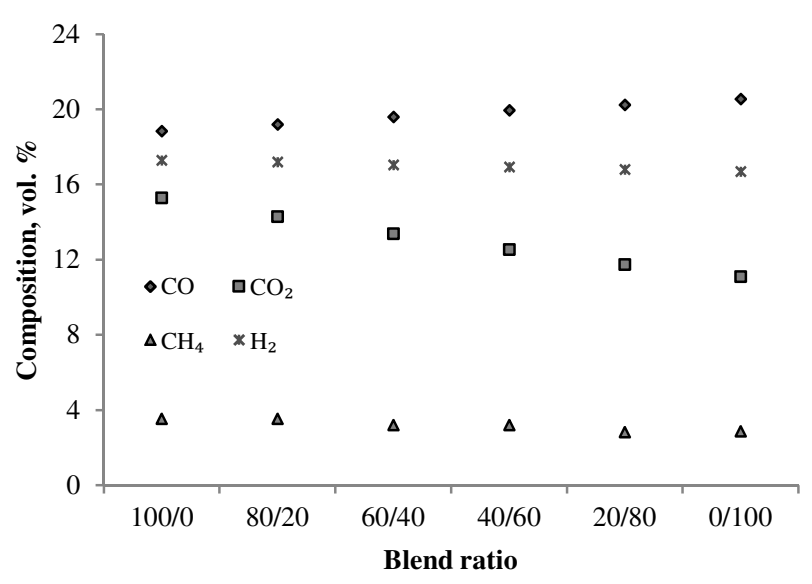

Fig. 4. Syngas components from downdraft gasification of OPF-PKS fuel mixes at $700^{\circ} \mathrm{C}$ and 0.25 ER.

\subsection{Higher heating value}

The higher heating value (HHV) of all the fuel mixes are shown in Fig. 5. The HHV of OPFEFB mixes show an increasing trend until 60/40 blend ratio before dropping, while OPFPKS mixes show a dropping HHV and OPF- PMF mixes show an increasing HHV, all with increasing ratio of secondary fuel content in the blends. Since HHV solely depends on the quantity of combustible components $\left(\mathrm{CO}, \mathrm{CH}_{4}\right.$ and $\left.\mathrm{H}_{2}\right)$ in syngas, any compositional change of the components in syngas will reflect on the HHV. The increasing productions of $\mathrm{CO}$ and $\mathrm{H}_{2}$ with increasing blend ratio in the OPF-PMF fuel mixes led to the increasing trend of HHV, whereby the continuous drop of HHV in the OPF-PKS fuel mixes was the result of the dropping $\mathrm{CH}_{4}$. The similar observation was seen in the case of the OPF-EFB fuel mixes, where the changes in $\mathrm{CH}_{4}$ were reflected in the HHV. Due to the relatively high $\mathrm{HHV}$ value of $\mathrm{CH}_{4}\left(39.82 \mathrm{MJ} / \mathrm{Nm}^{3}\right)$ as compared to that of $\mathrm{CO}\left(12.63 \mathrm{MJ} / \mathrm{Nm}^{3}\right)$ and $\mathrm{H}_{2}\left(12.74 \mathrm{MJ} / \mathrm{Nm}^{3}\right)$, even a small change in $\mathrm{CH}_{4}$ composition will contribute to a large alteration in syngas HHV. Despite the HHV trends as observed in all fuel mixes, it is worth to note that the difference in the minimum and maximum HHV for each mix remained below 3.84\% for OPF-EFB mixes, $3.2 \%$ for OPF-PKS mixes and $6.1 \%$ for OPF-PMF mixes. The HHV for all fuel mixes of all blend ratios were found to be above the HHV range of syngas produced from the downdraft gasification of $100 \%$ OPF.

\subsection{Specific syngas yield}

The specific syngas yields for OPF-EFB, OPF-PKS and OPF-PMF mixes are shown in Figur6. Only OPF-PKS mix showed a noticeable dropping pattern with increasing blending ratio while OPF-EFB and OPF-PMF did not show any significant change. The decreasing specific syngas yield in OPF-PKS mix was contributed by the falling $\mathrm{CO}_{2}$ and $\mathrm{H}_{2}$ production with increasing blending ratio that consequently affected the total amount of syngas produced. However, the drop only accounted for around $7 \%$ of specific syngas yield and was considered uncritical. The range of the specific syngas yield for the OPF-EFB, OPF-PKS and OPF-PMF fuel mixes were $1.89-1.92 \mathrm{~m}^{3} / \mathrm{kg}, 1.78-1.93 \mathrm{Nm}^{3} / \mathrm{kg}$ and $1.89-1.91 \mathrm{Nm}^{3} / \mathrm{kg}$ respectively. The values were found to be rather low compared to the typical specific syngas yield of about $2.5 \mathrm{Nm}^{3} / \mathrm{kg}$. However, the comparatively low specific syngas yield in all fuel mixes was expected due to the low ER used in the experiments. 


\subsection{Carbon conversion efficiency}

The carbon conversion efficiency (CCE) for all fuel mixes are shown in Fig. 7. Only the OPF-PKS mix showed a significant dropping trend while the OPF-EFB and OPF-PMF did not show any evident change with increasing blending ratio. Since CCE highly depends on the syngas yield, any change in the latter will directly affect the CCE. In the case of OPFPKS mix, it suffered falling syngas yield with increasing blend ratio, thus causing the CCE to drop due to the reducing amount of solid carbon in the fuel being converted into gas. Nevertheless, all the CCE values were found to be above $70 \%$ and were considered sufficiently high. The OPF-EFB and OPF-PMF mixes showed 89-92\% of CCE in all blend ratios.

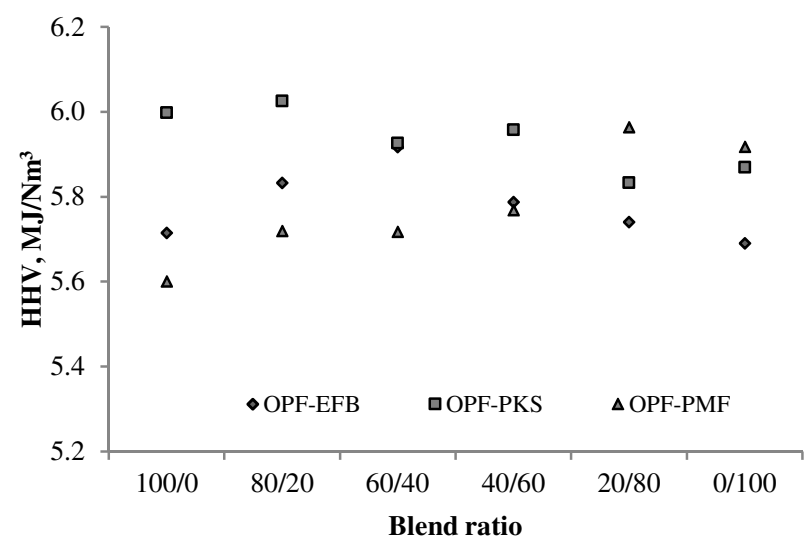

Fig. 5. HHV of syngas produced from downdraft gasification of OPF-EFB, OPF-PKS and OPF-PMF mixes at $700^{\circ} \mathrm{C}$ gasification temperature and $0.25 \mathrm{ER}$.

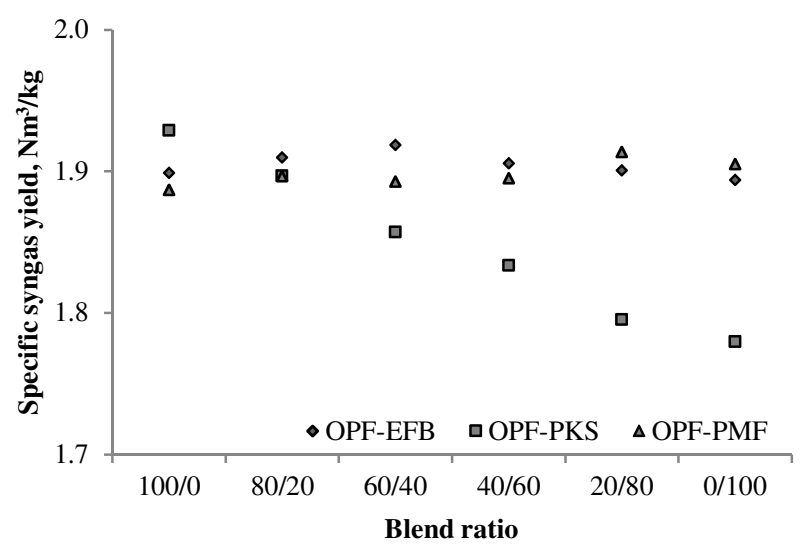

Fig. 6. Specific syngas yields from downdraft gasification of OPF-EFB, OPF-PKS and OPF-PMF fuel mixes at $700^{\circ} \mathrm{C}$ gasification temperature and $0.25 \mathrm{ER}$. 


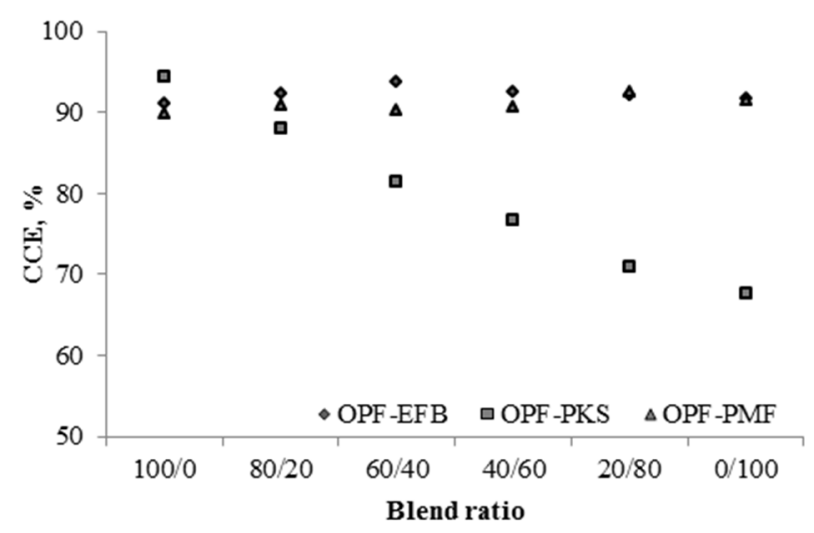

Fig. 7. CCE of downdraft gasification of OPF-EFB, OPF-PKS and OPF-PMF fuel mixes at $700^{\circ} \mathrm{C}$ gasification temperature and $0.25 \mathrm{ER}$.

\subsection{Cold gas efficiency}

The CGE of OPF-EFB, OPF-PKS and OPF-PMF fuel mixes are shown in Fig. 8. All fuel mixes show a dropping trend in the CGE with increasing blend ratio. The highest and lowest CGE were observed in the OPF-PKS mix, particularly due to the drops in HHV and specific syngas yield but with increasing calorific value of each mix with increasing blend ratio. The OPF-PKS mix suffered $23.65 \%$ drop as a result of around $2.1 \%$ drop in HHV. The similar trend observed in the OPF-EFB and OPF-PMF mixes, although insignificant, was also due to the same cause. Nevertheless, the CGE in all fuel mixes were found to be considerably high compared to the typical CGE obtained from the gasification of $100 \%$ OPF, which normally was around $63-68 \%$.

\section{Conclusions}

From the analyses of results obtained from the experiments, it can be fairly concluded that the quality of syngas produced from the OPF-EFB, OPF-PMF and OPF-PKS fuel mixes of various blending ratio satisfied all the quality requirements based on the downdraft gasification of $100 \%$ OPF solid fuel. The blending ratios were found to have not significantly affected the syngas qualities. Therefore, all the fuel mixes of all blending ratios were considered, although primitively, acceptable as alternative gasification fuels in the event of OPF fuel shortage. However, the effects of ER and gasification temperatures still need to be carried out in order to further asses and qualify the fuel mixes for co-gasification.

\section{References}

1. L. T. De Luca, MPOB. Oil palm \& the environment. Propulsion physics (EDP Sciences, Les Ulis, 2009)

2. Dept. Statistics Malaysia. Press release: selected agricultural indicators Malaysia 2015. (2015)

3. Abdullah N. and Sulaiman F. InTech. pp. 75-100 (2013)

4. MPOB. Production of crude palm oil Jan-Dec 2015 (2016)

5. Hoong S.S. Palm oil \& related products. The Chinese Chamber of Commerce \& Industry of Kuala Lumpur \& Selangor Bulletin: 338. pp. 11-15 (2011). 
6. MARDI. Oil palm frond pellet as animal feed. (2015)

7. Basu P. Biomass gasification and pyrolysis: practical design and theory,(Academic Press, 2010)

8. Inayat A., Ahmad M.M., Mutalib M. I. A., Yusup S. and Khan Z. Advanced Materials Research. 1133. pp. 654-658 (2016)

9. Mohammed M.A.A., Salmiaton A., Wan Azlina W.A.K.G., Mohammad Amran M.S., Fakhru'l-Razi A. and Taufiq-Yap Y.H. Renew. Sust. Energ. Rev., 15 (2). pp. 1258-1270, (2011).

10. Mohammed M.A.A., Salmiaton A., Wan Azlina W.A.K.G., Mohammad Amran. Bioresource Technol., 110. pp. 628-636, (2012)

11. Sivasangar S., Zainal A., Salmiaton A. and Taufiq-Yap Y.H., Fuel. 143. pp. 563-569, (2015)

12. Inayat M., Sulaiman S.A., Abd Jamil A., Guangul F.M. and Atnaw S.M. Proceedings of the International Conference on Global Sustainability and Chemical Engineering. pp. 203-210 (2014)

13. Sulaiman S.A., Muhammad F.K., Moni M.N.Z., and Atnaw S.M, Asian J. Sci. Res. 6 (2). pp. 245-253 (2013)

14. Moni M.N.Z. and Sulaiman S.A., Asian J. Sci. Res. 6 (2). pp. 197-206 (2013)

15. Moni M.N.Z and Sulaiman S.A., Appl. Mech. Mater., 699. pp. 480-485 (2014) 